\title{
A case of thyroid storm complicated by acute hepatitis due to propylthiouracil treatment
}

\author{
Nicola Tufton, Nazhri Hashim, Candy Sze and Mona Waterhouse
}

Bartshealth NHS Trust, St Bartholomew's Hospital, West Smithfield, London EC1A 7BE, UK

Correspondence

should be addressed

to $\mathrm{N}$ Tufton

Email

nicola.tufton1@nhs.net

\section{Summary}

A 57-year-old female presented 17 days after treatment with radioactive iodine (RAl) for difficult-to-control hyperthyroidism. She was febrile, had a sinus tachycardia, and was clinically thyrotoxic. Her thyroid function tests showed a suppressed TSH $<0.02 \mathrm{mU} / \mathrm{l}$, with free thyroxine $\left(\mathrm{FT}_{4}\right)>75 \mathrm{pmol} / \mathrm{l}$ and total triiodothyronine $\left(\mathrm{TT}_{3}\right) 6.0 \mathrm{nmol} / \mathrm{l}$. She was diagnosed with thyroid storm and was managed with i.v. fluids, propylthiouracil (PTU) $200 \mathrm{mg}$ four times a day, prednisolone $30 \mathrm{mg}$ once daily and propanolol $10 \mathrm{mg}$ three times a day. She gradually improved over 2 weeks and was discharged home on PTU with $\beta$ blockade. On clinic review 10 days later, it was noted that, although she was starting to feel better, she had grossly abnormal liver function (alanine transaminase (ALT) $852 \mathrm{U} / \mathrm{l}$, bilirubin $46 \mu \mathrm{mol} / \mathrm{l}$, alkaline phosphatase (ALP) $303 \mathrm{U} / \mathrm{l}$, international normalized ratio (INR) 0.9 , platelets $\left.195 \times 10^{9} / \mathrm{l}\right)$. She was still mildly thyrotoxic (TSH $<0.02 \mathrm{mU} / \mathrm{l}, \mathrm{FT}_{4} 31 \mathrm{pmol} / \mathrm{l}$ $\left.\mathrm{TT}_{3} 1.3 \mathrm{nmol} / \mathrm{l}\right)$. She was diagnosed with acute hepatitis secondary to treatment with PTU. Ultrasound showed mild hepatic steatosis. PTU was stopped and she was managed with fluids and prednisolone 60 mg once daily and continued $\beta$ blockade. Her liver function gradually improved over 10 days (bilirubin $9 \mu \mathrm{mol} / \mathrm{l}$, ALT 164 U/l, ALP 195 U/l, INR 0.9, platelets $323 \times 10^{9} /$ ) with conservative management and had normalised by clinic review 3 weeks later. This case highlights the potentially fatal, but rare, complications associated with both RAI and PTU, namely, thyroid storm and acute hepatitis respectively.

\section{Learning points:}

- Thyroid storm is an important, albeit rare, endocrinological emergency.

- Thyroid storm following RAI treatment is extremely rare.

- Management is with i.v. fluids, $\beta$ blockade, anti-thyroid drugs and steroids.

- High dose glucocorticoid steroids can block the peripheral conversion of $T_{4}$ to active $T_{3}$.

- Liver dysfunction, acute hepatitis and potential hepatic failure are significant adverse drug reactions known to occur with PTU treatment. Supervising clinicians should be vigilant for evidence of this developing and intervene accordingly.

- Clinicians need to be aware of possible interactions between regular paracetamol use and PTU in predisposing to liver impairment. 


\section{Background}

Thyroid storm is an important, albeit rare, endocrinological emergency that can present to an outpatient clinic, general practice or medical admission unit. Thyroid storm post-RAI treatment is an extremely rare phenomenon. Early identification and prompt initiation of treatment are needed to minimise complications and prevent the mortality associated with this condition. Propylthiouracil (PTU) was the preferred treatment for thyroid storm due to its properties of inhibiting peripheral conversion of thyroxine $\left(\mathrm{T}_{4}\right)$ to triiodothyronine $\left(\mathrm{T}_{3}\right)$ and therefore gaining rapid control of the thyrotoxicosis. However, clinicians need to be aware of the potential adverse drug reactions with high dose PTU treatment and what management options may be necessary for such cases.

\section{Case presentation}

A 57-year-old female presented 17 days after treatment with radioactive iodine (RAI) for difficult-to-control hyperthyroidism. She had undergone a right thyroidectomy 18 years previously for a right dominant nodule within a multinodular goitre. Histology demonstrated a colloid adenoma and associated lymphocytic infiltration; therefore, she did not proceed to a total thyroidectomy and subsequently was under surveillance for her thyroid function. Her free $\mathrm{T}_{4}\left(\mathrm{FT}_{4}\right)$ levels had gradually increased over a 2-year period and she was commenced on Carbimazole $5 \mathrm{mg}$ once daily. She underwent a pertechnetate uptake scan that demonstrated intense uniform increased uptake in the residual left thyroid lobe, with no uptake in the right thyroid bed (see Fig. 1). Technetium uptake was $2.3 \%$. Definitive treatment was discussed, but due to her social circumstances, she declined RAI treatment and, therefore, was discharged on long-term low dose Carbimazole. She remained well controlled on this dose for 3 years, but then her symptoms returned with biochemical evidence of recurrence of thyrotoxicosis and she opted for RAI treatment.

She stopped her Carbimazole 2 weeks before treatment and received $600 \mathrm{MBq}$ of I-131. Prior to treatment her thyroid stimulating hormone (TSH) was $0.01 \mathrm{mU} / \mathrm{l}$, with $\mathrm{FT}_{4} 20 \mathrm{pmol} / \mathrm{l}$. When she presented 17 days after her RAI treatment, she was experiencing hot flushes, palpitations, extreme fatigue, diarrhoea, nausea, pain in her neck and dysphagia. On examination she had a BMI of $32 \mathrm{~kg} / \mathrm{m}^{2}$, was febrile at $39.4^{\circ} \mathrm{C}$, had a sinus tachycardia at $130 \mathrm{bpm}$, blood pressure (BP) 120/76 $\mathrm{mmHg}$, with mild pedal oedema and was clinically thyrotoxic, with tremor, lid lag and a tender goitre with an audible bruit. She scored 60 points on the Burch and Wartofsky (1) scoring system.

\section{Investigation}

On presentation following her RAI treatment, TSH was $<0.02 \mathrm{mU} / \mathrm{l}$ (normal range: $0.3-4 \mathrm{mU} / \mathrm{l}$ ), $\mathrm{FT}_{4}>75 \mathrm{pmol} / \mathrm{l}$ (normal range: $10.5-24.5 \mathrm{pmol} / \mathrm{l}$ ), total $\mathrm{T}_{3}\left(\mathrm{TT}_{3}\right) 6.0 \mathrm{nmol} / \mathrm{l}$ (1-2.7 nmol/l) and normal renal and liver function (bilirubin $5 \mu \mathrm{mol} / \mathrm{l}$, alkaline phosphatase (ALP) $79 \mathrm{U} / \mathrm{l}$, alanine transaminase (ALT) $32 \mathrm{U} / \mathrm{l}$ ). These were monitored daily. Septic screen was negative, including chest radiograph, urine and blood cultures. Our laboratory's upper limit is $75 \mathrm{pmol} / \mathrm{l}$ and her thyroid function did not show any improvement in the first $72 \mathrm{~h}$. The biochemistry laboratory was asked to perform dilution studies on the $\mathrm{FT}_{4}$ samples. Her $\mathrm{FT}_{4}$ on dilution was $154 \mathrm{pmol} / \mathrm{l}$ on day 1 and improved to $113 \mathrm{pmol} / \mathrm{l}$ by day 4 and $75 \mathrm{pmol} / \mathrm{l} 7$ days after presentation. Although not standardised, the dilution studies of $\mathrm{FT}_{4}$ proved extremely useful in the management and monitoring of our patient.

On discharge TSH was $<0.02 \mathrm{mU} / \mathrm{l}$, with a $\mathrm{FT}_{4}$ $47.1 \mathrm{pmol} / \mathrm{l}, \mathrm{TT}_{3} 1.7 \mathrm{pmol} / \mathrm{l}$ and normal liver function (bilirubin $2 \mu \mathrm{mol} / \mathrm{l}$, ALP $96 \mathrm{U} / \mathrm{l}$, ALT $20 \mathrm{U} / \mathrm{l}$ ).

\section{Treatment}

She was diagnosed with thyroid storm and was managed in a side room with i.v. fluids, PTU $200 \mathrm{mg}$ four times per day, propanolol $10 \mathrm{mg}$ three times per day, prednisolone $30 \mathrm{mg}$ once daily and regular paracetamol. Attempts were made to up titrate her $\beta$ blockade, but she did not tolerate higher doses due to symptomatic hypotension. She gradually improved over 2 weeks and was discharged home on PTU $200 \mathrm{mg}$ four times per day, $\beta$ blockade of propanolol $10 \mathrm{mg}$ three times per day, regular paracetamol and a reducing dose of prednisolone of $5 \mathrm{mg}$ every 5 days.

As her thyroid storm had been triggered by RAI, she was not treated with iodine (2), as it was felt that not only would her iodine stores be saturated and therefore not beneficial but also may in fact worsen her clinical state, in accordance with escape from the Wolff-Chaikoff effect (3).

On clinic review 10 days after discharge, she was feeling slightly better but reported ongoing fatigue and a new pruritus. Her thyroid function had improved (TSH $\left.<0.02 \mathrm{mU} / \mathrm{l}, \mathrm{FT}_{4} 31 \mathrm{pmol} / \mathrm{l}, \mathrm{TT}_{3} 2.1 \mathrm{nmol} / \mathrm{l}\right)$, but her liver function tests were grossly abnormal (bilirubin $46 \mu \mathrm{mol} / \mathrm{l}$, ALT 852 U/l, ALP $303 \mathrm{U} / \mathrm{l}$, international normalized ratio (INR) 0.9). 


\section{Technetium Study}

\section{Uptake function $\quad=2.35 \%$ Normal Range: $(0.40-4.0)$}

\section{Injected activity (scan tine) $=82.0 \mathrm{MBq}$ \\ Systen sensitivity $\quad=66.0 \mathrm{cps} / \mathrm{MBq}$}

\section{Figure 1}

Technetium study.

She was diagnosed with liver impairment secondary to treatment with PTU and an urgent admission was arranged. Hepatitis serology was negative and an ultrasound showed mild hepatic steatosis only. Her PTU and paracetamol were stopped and she was managed with i.v. fluids and prednisolone $60 \mathrm{mg}$ and continued $\beta$ blockade.

Liver biopsy is the gold standard for diagnosis of PTU-induced hepatic injury, but diagnosis can often be inferred from the onset of hepatic dysfunction from the initiation of PTU therapy (4). Recovery varies greatly between complete remission on cessation of the drug and supportive treatment, to requiring plasmapheresis or haemodialysis for the correction of coagulopathy and encephalopathy, to liver transplantation and a lifetime of immunosuppressive treatment (2), (3), (4). Our patient did not require liver biopsy as her liver function gradually 
Table 1 Liver function results per days from radioactive treatment.

\begin{tabular}{l}
\hline $\begin{array}{l}\text { Days post-RAI } \\
\text { treatment }\end{array}$ \\
\hline 17 \\
28 \\
37 \\
38 \\
39 \\
40 \\
41 \\
43 \\
45 \\
65 \\
\hline
\end{tabular}

\begin{tabular}{c}
\hline BP $(\mathrm{mmHg})$ \\
\hline $120 / 76$ \\
$151 / 95$ \\
$135 / 74$ \\
$130 / 74$ \\
$150 / 72$ \\
$125 / 90$ \\
$140 / 84$ \\
$130 / 84$ \\
$145 / 94$ \\
\end{tabular}

\begin{tabular}{c}
\hline HR (bpm) \\
\hline 130 \\
73 \\
76 \\
74 \\
60 \\
70 \\
66 \\
67 \\
62 \\
\hline
\end{tabular}

\begin{tabular}{c}
\hline Bilirubin $(\mu \mathrm{mol} / \mathrm{l})$ \\
\hline 5 \\
2 \\
46 \\
39 \\
21 \\
15 \\
10 \\
9 \\
9 \\
6 \\
\hline
\end{tabular}

\begin{tabular}{c}
\hline ALT (U/I) \\
\hline 32 \\
20 \\
852 \\
698 \\
564 \\
421 \\
284 \\
205 \\
164 \\
21 \\
\hline
\end{tabular}

\begin{tabular}{|c|c|}
\hline ALP $(U / I)$ & INR \\
\hline 79 & 1.0 \\
\hline 96 & \\
\hline 303 & 0.9 \\
\hline 306 & \\
\hline 270 & \\
\hline 244 & \\
\hline 213 & \\
\hline 195 & \\
\hline 195 & 0.9 \\
\hline 123 & \\
\hline
\end{tabular}

$H R$, heart rate.

improved over a 10-day admission (bilirubin $9 \mu \mathrm{mol} / \mathrm{l}$, ALT $164 \mathrm{U} / \mathrm{l}$, ALP $195 \mathrm{U} / \mathrm{l})$ with cessation of PTU, and her prednisolone was weaned down (see Table 1).

\section{Outcome and follow-up}

Liver function had completely normalised by clinic review 3 weeks after discharge, and on review 6 weeks later, she had become hypothyroid (see Tables 1 and 2).

\section{Discussion}

Radiation thyroiditis is a painful inflammation of the thyroid gland and occurs in 1\% of patients receiving RAI treatment and can be associated with exacerbation of the thyrotoxicosis due to the destruction-mediated release of the thyroid hormone (5). Thyroid storm is usually precipitated by a second superimposed insult, such as infection or autoimmune triggers (e.g., diabetic ketoacidosis, hyperosmolar hyperglycaemic state), myocardial infection and pregnancy, as well as surgical treatment for hyperthyroidism, withdrawal of anti-thyroid medications, thyroid hormone overdose or treatment with biological agents (3), (6). However, thyroid storm following RAI treatment is extremely rare (6), (7).

The aims of treatment in thyroid storm are to decrease thyroid hormone synthesis (anti-thyroid medications), prevent thyroid hormone release (iodine, lithium), decrease peripheral action of circulating thyroid hormone by blocking $\mathrm{T}_{4}$ to $\mathrm{T}_{3}$ conversion (PTU, $\beta$ blockade, corticosteroids and rarely amiodarone) and support the cardiovascular system ( $\beta$ blockade, i.v. fluids), as well as treating the precipitating condition. Cholestyramine can be used to block enterohepatic circulation by reducing reabsorption of the metabolized thyroid hormone (3).

PTU is a thioamide derivative and inhibits both the enzyme thyroid peroxidise and $5^{\prime}$-deiodinase and therefore blocks iodine organification and peripheral conversion of $\mathrm{T}_{4}$ into active $\mathrm{T}_{3}$. There are common and mild adverse effects with anti-thyroid medications, occurring

Table 2 Clinical parameters and TFT results per days from radioactive treatment.

\begin{tabular}{|c|c|c|c|c|c|c|}
\hline $\begin{array}{l}\text { Days post-RAI } \\
\text { treatment }\end{array}$ & Weight (kg) & $\mathbf{B P}(\mathrm{mmHg})$ & HR (bpm) & TSH (mU/l) & $\mathbf{F T}_{\mathbf{4}}(\mathrm{pmol} / \mathrm{l})$ & $\mathbf{T T}_{3}(\mathrm{nmol} / \mathrm{l})$ \\
\hline Pre treatment & 94 & & & 0.01 & 20 & \\
\hline 17 & 90.8 & $120 / 76$ & 130 & $<0.02$ & $>75$ & 6.0 \\
\hline 18 & & $120 / 68$ & 90 & $<0.02$ & $>75$ & \\
\hline 20 & & $135 / 95$ & 100 & $<0.02$ & 75 & \\
\hline 24 & & $138 / 66$ & 78 & $<0.02$ & 56.8 & \\
\hline 26 & & $130 / 73$ & 68 & $<0.02$ & 56.2 & 2.1 \\
\hline 28 & 91 & $151 / 95$ & 73 & $<0.02$ & 47.1 & 1.7 \\
\hline 37 & 92.2 & $135 / 76$ & 76 & $<0.02$ & 31 & 1.3 \\
\hline 43 & & $140 / 84$ & 66 & 0.03 & 14.8 & \\
\hline 45 & & $152 / 100$ & 69 & 0.02 & 12.6 & \\
\hline 65 & 97 & & & 29.3 & 4.1 & \\
\hline
\end{tabular}

TFT, thyroid function test; HR, heart rate. 
in $5-20 \%$ of patients, including rash and gastrointestinal upset. The rare risk of agranulocytosis occurs at a rate of $0.2-0.5 \%$. The risk of hepatotoxicity can be up to $25 \%$, with severe liver failure occurring in $<1 \%$, and appears to be higher in children and adolescence (8), (9). Other reported links include increased risk of vasculitis, glomerulonephritis and associated positive titers of antineutrophil cytoplasmatic antibody (8).

PTU was the preferred treatment for thyroid storm due to its properties of inhibiting peripheral conversion of $\mathrm{T}_{4}$ to $\mathrm{T}_{3}$ and therefore gaining rapid control of the thyrotoxicosis. However, clinicians need to be aware of the potential life-threatening side effects of acute liver failure with PTU treatment (4), (8), (9) and how to manage such cases should they occur. PTU is the third most common single drug cause of drug-induced liver injury and druginduced liver transplantation (8). Severe PTU-induced hepatotoxicity is postulated to be a dose-independent idiosyncratic hypersensitivity reaction (4), (9).

PTU-induced hepatitis was first described in 1947 (10) and the first case of PTU-induced fulminant hepatic failure occurred in 1953 (11), although these are rare adverse effects of this treatment. Acute hepatitis has been reported with a prevalence of $0.1-1.2 \%$ (12), but the mortality associated with this can be as high as $25 \%$ (2), (8). Therefore, it is imperative that liver function is checked before initiating treatment and monitored throughout.

A literature review identified 30 cases of PTUassociated hepatotoxicity between 1966 and 1996. Several early prognostic factors were identified to associated with worse outcomes including patients age $<11$ years or $>40$ years, duration of jaundice of $>7$ days, before the onset of encephalopathy, serum bilirubin $>300 \mu \mathrm{mol} / \mathrm{l}$ and prothrombin time $>50 \mathrm{~s}$ (2). A study looking at 40 years of safety data in the United States identified more than 30 cases of PTU-induced liver failure occurring in individuals aged 6-62 years. Of these, 14 occurred in paedriatric cases, 18 recovered with conservative management, transplantation was required in three persons and nine deaths were reported (8).

In many cases of thyroid storm, iodine can be used in the form of potassium iodide, Lugol's solution or iapanoic acid to gain rapid control of thyrotoxicosis. The WolffChaikoff effect describes the effect of large doses of iodine suppressing thyroid hormone release; however, escape from this effect can occur (usually 10-14 days) after the commencement of iodine therapy, and after this further therapy, at best, it is unlikely to be beneficial and, at worst, could exacerbate the situation (3). This is often a holding measure to gain control of the thyroid storm until emergency thyroidectomy can be undertaken. In this case the trigger was treatment with RAI, and the time delay to presentation means the patient would already be in the 'escape' phase.

Glucocorticoid steroids are useful in the treatment of thyroid storm. In high doses they block the peripheral conversion of $\mathrm{T}_{4}$ to $\mathrm{T}_{3}$ in addition to their beneficial antiinflammatory effects on the thyroid gland itself.

In overdose, paracetamol can cause liver impairment as it can deplete stores of liver glutathione. In healthy adults, $\sim 15 \mathrm{~g}$ acetaminophen is required to deplete liver glutathione by $70 \%$ in a $70 \mathrm{~kg}$ person. Hepatotoxicity can develop at more modest doses in alcoholic patients. The use of regular paracetamol may have predisposed our patient to the adverse hepatic effects of PTU. Salicylates should be avoided as they are associated with displacement of thyroid hormone binding from thyroid binding globulin (3).

Thyroid storm is an important, but rare, endocrinological emergency. Thyroid storm following RAI treatment is an extremely rare phenomenon. Early identification and prompt initiation of anti-thyroid medication, high dose steroids and $\beta$ blockade are needed to minimise complications and prevent the mortality associated with this condition that can occur if left untreated.

Declaration of interest

The authors declare that there is no conflict of interest that could be perceived as prejudicing the impartiality of the research reported.

\section{Funding}

This research did not receive any specific grant from any funding agency in the public, commercial or not-for-profit sector.

\section{Patient consent}

The patient has provided informed written consent for publication of her case.

Author contribution statement

All co-authors contributed to the care of the patient and the writing of the case report.

\section{References}

1 Burch HB \& Wartofsky L 1993 Life-threatening thyrotoxicosis. Thyroid storm. Endocrinology and Metabolism Clinics of North America 22 263-277. 
2 Williams KV, Nayak S, Becker D, Reyes J \& Burmeister LA 1997 Fifty years of experience with propylthiouracil-associated hepatotoxicity: what have we learned? Journal of Clinical Endocrinology and Metabolism 82 1727-1733. (doi:10.1210/jcem.82.6.4011)

3 Carroll R \& Matfin G 2010 Endocrine and metabolic emergencies: thyroid storm. Therapeutic Advances in Endocrinology and Metabolism 1 139-145. (doi:10.1177/2042018810382481)

4 Carrion AF, Czul F, Arosemena LP, Selvaggi G, Garcia MT, Tekin A, Tzakis AG, Martin P \& Ghanta RK 2010 Propylthiouracil-induced acute liver failure: role of liver transplantation. International Journal of Endocrinology 2010 1-5. (doi:10.1155/2010/910636)

5 Douglas RS 2011 Radioiodine therapy for hyperthyroidism. New England Journal of Medicine 364 542-550. (doi:10.1056/NEJMct1007101)

6 Vijayakumar V, Nusynowitz ML \& Ali S 2006 Is it safe to treat hyperthyroid patient with I-131 without fear of thyroid storm. Annals of Nuclear Medicine 20 383-385. (doi:10.1007/BF03027372)

7 Shafer RB \& Nuttall FQ 1975 Acute changes in thyroid function in patients treated with radioactive iodine. Lancet 2 635-637. (doi:10. 1016/S0140-6736(75)90117-8)
8 Rivkees SA \& Szarfman A 2010 Dissimilar hepatotoxicity profiles of propylthiouracil and methimazole in children. Journal of Endocrinology and Metabolism 95 3260-3267. (doi:10.1210/jc.2009-2546)

9 Food and Drug Administration. Propylthiouracil tablets. 2010. http:// www.fda.gov/Safety/MedWatch/SafetyInformation/ucm209256.htm (accessed 20 April 2015)

10 Livingston HJ \& Livingston SF 1947 Agranulocytosis and hepatocellular jaundice: toxic reaction following propylthiouracil therapy. Journal of the American Medical Association 135 422-425. (doi:10.1001/jama.1947. 02890070024006)

11 Eisen MJ 1953 Fulminant hepatitis during treatment with propylthiouracil. New England Journal of Medicine 249 814-816. (doi:10.1056/NEJM195311122492007)

12 Kim HJ, Kim BH, Han YS, Yang I, Kim KJ, Dong SH, Kim HJ, Chang YW, Lee JI \& Chang R 2001 The incidence and clinical characteristics of symptomatic propylthiouracil-induced hepatic injury in patients with hyperthyroidism: a single-centre retrospective study. American Journal of Gastroenterology 96 165-169. (doi:10.1111/j.1572-0241.2001. 03469.x)

Received in final form 4 July 2015

Accepted 16 July 2015 